\title{
Biological treatability study for refinery wastewater using bench scale sequencing batch reactor systems
}

\author{
S. R. M. Kutty, H. A. Gasim, P. F. Khamaruddin \\ \& A. Malakahmad \\ Universiti Teknologi PETRONAS, Malaysia
}

\begin{abstract}
A petroleum refinery facility discharge wastewater with average influent COD concentration of approximately $500-750 \mathrm{mg} / \mathrm{L}$ during the period of this study. Study on the treatability of the petroleum refinery effluent wastewater was conducted using bench scale biological sequencing batch reactor systems. Six sequencing batch reactors (SBR) each of $2 \mathrm{~L}$ liquid volume were operated at a 24 hours cycle. The SBRs were operated in various anaerobically stirred and aerobic modes. The average COD removals percentages for the aerobic reactor, combined anaerobic-aerobic reactors and aerobic mixed with domestic wastewater were found to be approximately, $91 \%, 91 \%$, and $88 \%$ respectively, with its final average effluent COD of $63 \mathrm{mg} / \mathrm{L}, 65 \mathrm{mg} / \mathrm{L}$, and $44 \mathrm{mg} / \mathrm{L}$, respectively.
\end{abstract}

Keywords: sequencing batch reactor, petroleum refinery wastewater, COD.

\section{Introduction}

Petroleum refining involves the transformation of crude oil into final useful products such as gasoline, gas oil, kerosene and jet fuel, and petrochemical feed stocks. The refined products are produced after a series of separation and treatment processes. After initial crude desalting and fractionation, several treatment and conversion processes are employed to reach the final blending stocks [1]. These activities involve consumption of huge amounts of water and will lead to the production of wastewater streams of which characteristics are very much dependent on the complexity and number of processes in a refinery 
plant [2]. Based on the environmental quality act, wastewater generated via refinery processes must be treated before discharge [3]. There are several treatment methods based on the type and concentrations of contaminants such as physical, chemical and biological processes [4]. Physical treatment methods for instance, separation and adsorption are associated with the disadvantage of toxic compounds generation. Chemical precipitation also results in production of excess sludge. In addition, both physical and chemical treatment methods need to be accompanied by post treatment processes which make the treatment process more costly. Unlike them, biological treatment methods are costeffective as they do not require high dosages of chemical materials and sophisticated devices. It can also be considered environmental friendly as less sludge is produced. Many researchers have successfully used biological methods for treatment of refinery wastewater [5-8].

Treatment of refinery wastewater was carried out in this study for a refinery facility that was looking for an alternative wastewater treatment method to ensure that the company will meet the regulatory limit of effluent set by the environment quality act. Current treatment method is not fully capable to treat the wastewater presumably due to changes in the constituents. Currently the wastewater treatment system consists of an oxidation pond and a final polishing pond. It is also noted that the performance of the oxidation pond varied.

From previous biodegradability study results, it was shown that the wastewater from petroleum refinery was ultimately biodegradable both aerobically as well as anaerobically [9]. A treatability study was proposed to the refinery to treat the waste stream biologically using bench scale sequencing batch reactors (SBR).

The objective of this study was to investigate the biodegradability of refinery wastewater. The study was to evaluate the performance of organic degradation of the wastewater sources using sequencing batch reactors operated in the aerobic, anaerobic mode as well as co-treating with municipal wastewater.

\section{Methodology}

\subsection{Experimental procedure}

Four different parallel batch treatment configurations were used to treat the petroleum refinery wastewater (Table 2). All the treatment configurations were operated in sequencing batch mode at a 24 hours cycle. The four reactors, each of $2 \mathrm{~L}$ sample volume, equipped with a mechanical stirrer were operated in an SBR mode with a 24 hours cycle. A supply of compressed air was provided for reactors operated in the aerobic mode. One litre of activated sludge from a sewage treatment plant was used as the biomass in all the aerobic reactors in treating 2-L of the wastewater samples. Reactor 2 was operated in the anaerobic stirred mode treating raw refinery wastewater, and was seeded with anaerobic sludge obtained from anaerobic tank. For this reactor, aeration was not provided in the cycle. 
The SBR feeding time, mixing period, settling and decanting was set at 30 minutes, 21 hours, 2 hours, and 30 minutes, respectively. Effluent from anaerobic reactor 2 that treats raw wastewater was fed into the aerobic reactor 3 . The aerobic reactor 4 treats low strength refinery wastewater mixed with domestic wastewater. Reactors 1,3 and 4 were operated in the aerobic mode. Feeding time, aeration period, settling and decanting was set at 30 minutes, 21 hours, 2 hours, and 30 minutes, respectively.

Two litres of wastewater was decanted at the end of the period. The reactors were then fed with fresh 2-L of wastewater for the next cycle. The decanted liquid at the end of the 24 hour cycle was then measured for chemical oxygen demand (COD).

Table 1: $\quad$ SBR treatability study.

\begin{tabular}{|c|l|c|c|c|c|c|}
\hline \multirow{2}{*}{ Reactor } & \multirow{2}{*}{ Treatment System } & \multicolumn{5}{|c|}{ Operation Cycle (hrs) } \\
\cline { 3 - 7 } & & Feeding & Mixing & Aeration & Settling & Decanting \\
\hline 1 & Aerobic for raw wastewater & 0.5 & \multicolumn{2}{|c|}{21} & 2 & 0.5 \\
\hline 2 & $\begin{array}{l}\text { Anaerobic for raw } \\
\text { wastewater }\end{array}$ & 0.5 & 21 & None & 2 & 0.5 \\
\hline 3 & $\begin{array}{l}\text { Aerobic treating Reactor 4 } \\
\text { Effluent }\end{array}$ & 0.5 & \multicolumn{2}{|c|}{21} & 2 & 0.5 \\
\hline 4 & $\begin{array}{l}\text { Aerobic for raw wastewater } \\
\text { (mixed with 50\% of } \\
\text { domestic wastewater) }\end{array}$ & 0.5 & \multicolumn{2}{|c|}{21} & 2 & 0.5 \\
\hline
\end{tabular}

\subsection{Sampling of wastewater}

The wastewater samples for the study were collected from the balancing tank in the refinery's wastewater treatment system that stored the refinery raw wastewater. $\mathrm{pH}$ of the wastewater was in the range of 6-7. Average COD concentration for raw wastewater was found to be approximately $712 \mathrm{mg} / \mathrm{L}$.

\section{Results and discussion}

\subsection{Overall result for SBR}

In this study, Fig. 1 illustrates the COD concentration (mg/L) at the end of each cycle vs days of SBR operation for the degradation of refinery raw wastewater operated under the aerobic and anaerobic mode.

Fig. 2 illustrates COD removal percentage at the end of every SBR cycle vs days for raw wastewater operated under the aerobic and anaerobic mode.

It can be observed that treatment of refinery raw wastewater using anaerobic SBR treatment achieved COD removal in the range of $30-40 \%$ at the end of the study period. However, treatment of refinery raw wastewater using aerobic SBR treatment achieved COD removals in the range of $80-90 \%$ after the third cycle. 


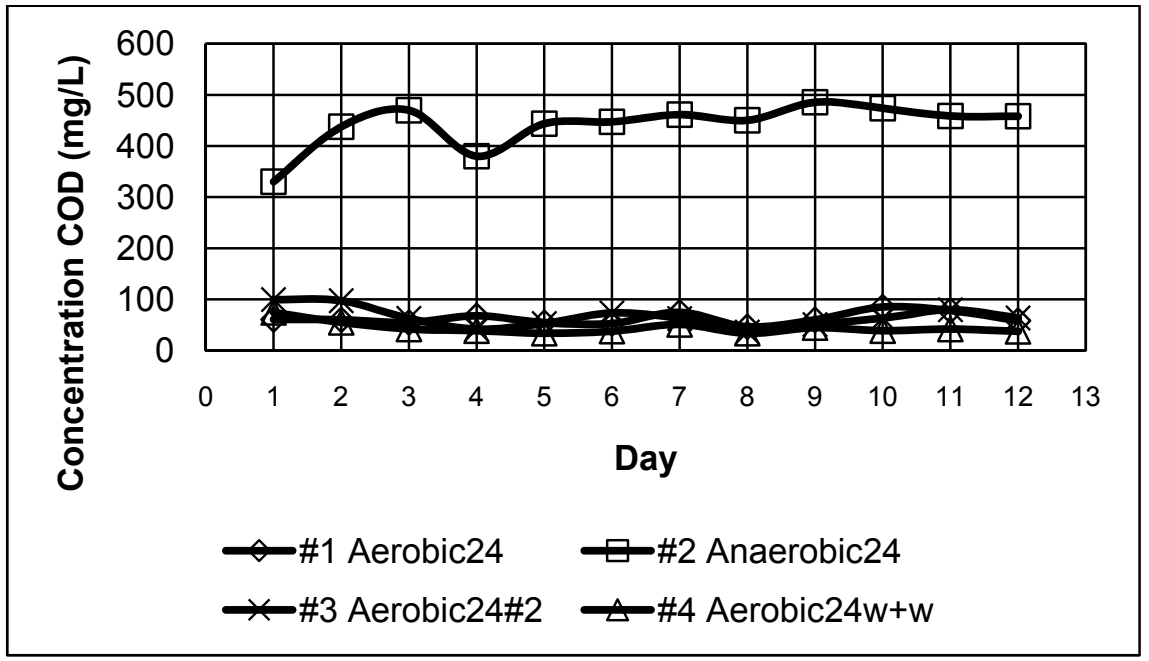

Figure 1: COD concentration vs sampling days for aerobic and anaerobic SBR treatment for raw wastewater.

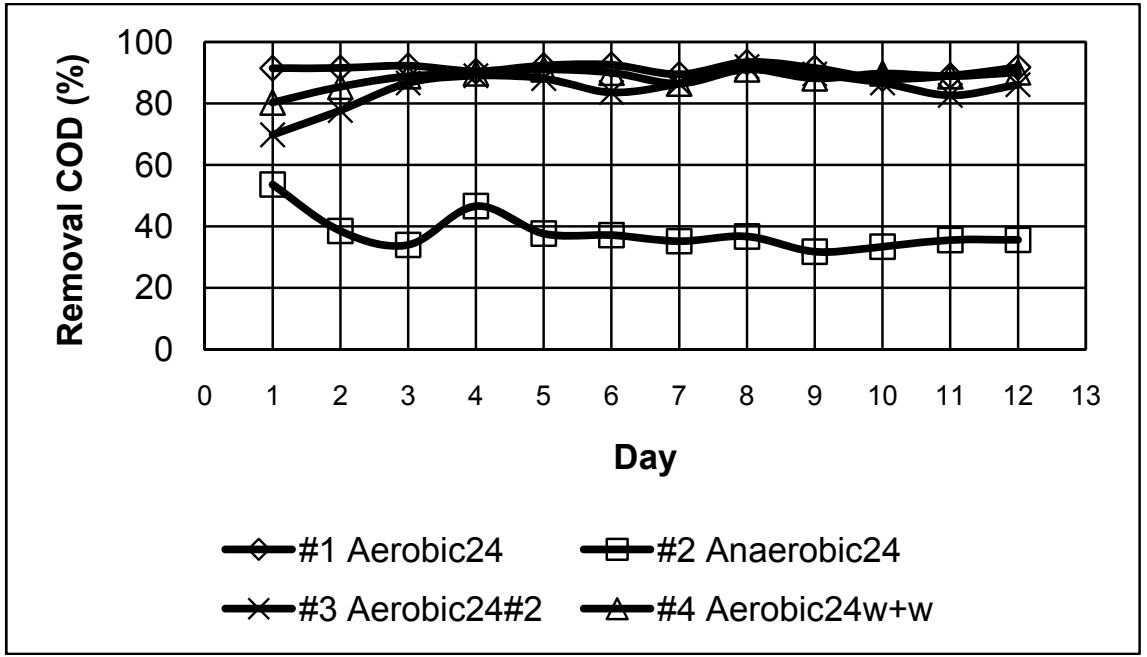

Figure 2: $\quad$ Removal COD percentage vs sampling days for aerobic and anaerobic SBR treatment for raw wastewater. 


\subsection{Result for aerobic SBR}

From Fig. 3, it can be observed that the aerobic SBR reactor \#3 that treats low strength refinery wastewater at a 24 hours cycle gave an average effluent COD concentration of $63 \mathrm{mg} / \mathrm{L}$. Influent COD concentration was $712 \mathrm{mg} / \mathrm{L}$. From Figure 3, it can be observed that this treatment gave an average COD removal of $91 \%$ throughout the study.

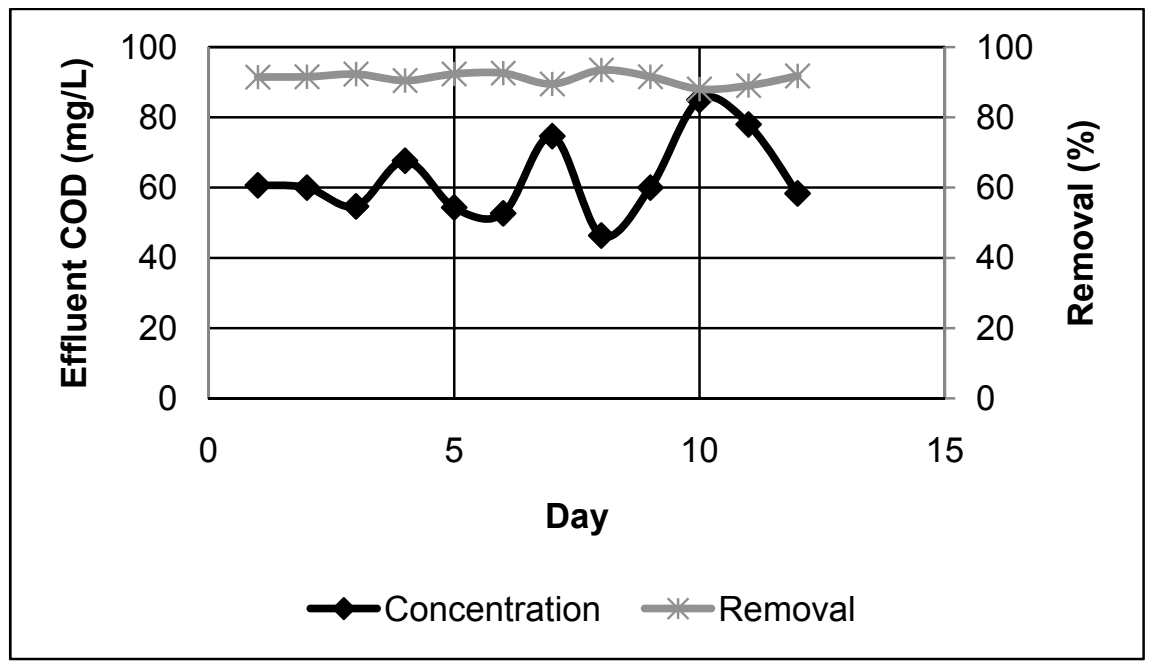

Figure 3: COD removals vs sampling days for SBR aerobic treatment for raw wastewater.

\subsection{Results for anaerobic-aerobic SBR}

The anaerobic SBR reactor $\# 2$ that treats refinery raw wastewater with a 24 hours cycle gave an average effluent COD concentration $441 \mathrm{mg} / \mathrm{L}$ (Fig. 4). Influent COD concentration was $712 \mathrm{mg} / \mathrm{L}$. It can be observed that an average COD removal of approximately $40 \%$ was achieved throughout the study period.

Effluent from the anaerobic SBR reactor \#2 was fed to be further treated in aerobic SBR reactor \#3 with 24 hours cycle. This enhanced the final effluent treatment as shown in Fig. 5. Influent COD concentration was approximately $441 \mathrm{mg} / \mathrm{L}$. Average effluent COD concentration was found to be approximately $65 \mathrm{mg} / \mathrm{L}$ with average COD removal of $85 \%$. The overall average COD removal of this combined treatment was found to be approximately $91 \%$ throughout the study period.

\subsection{Results for aerobic (mixed ww) SBR}

Another treatment approach conducted was to operate an aerobic SBR reactor \#4 that was fed with refinery raw wastewater combined with domestic wastewater. 


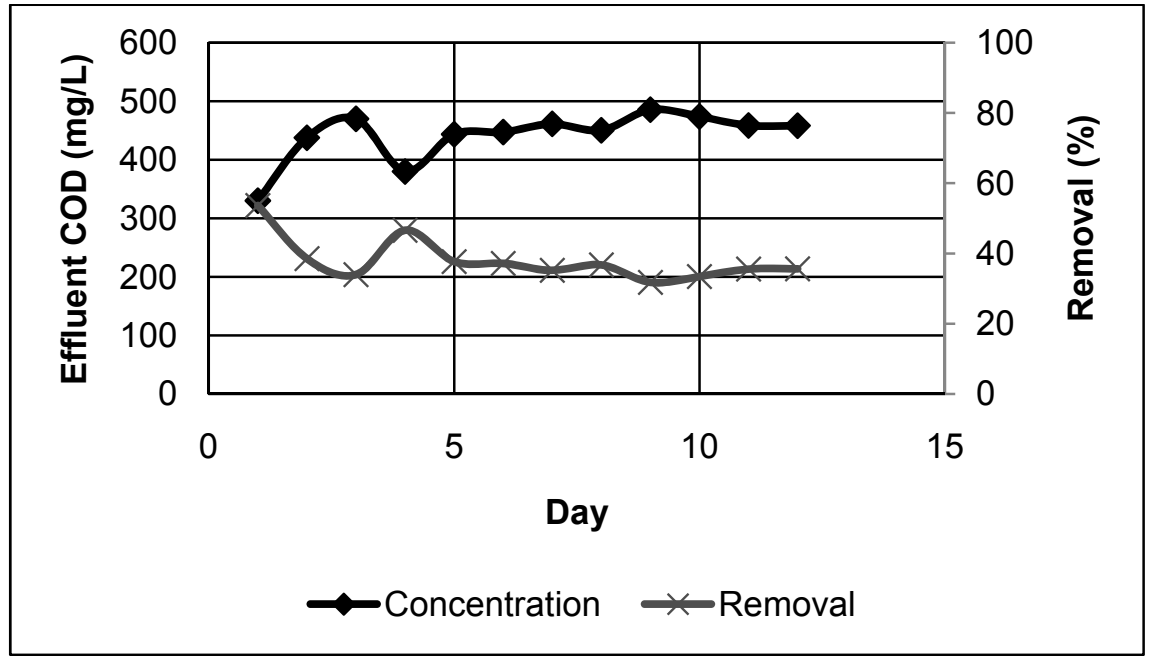

Figure 4: COD removals vs sampling days for SBR anaerobic treatment for raw wastewater.

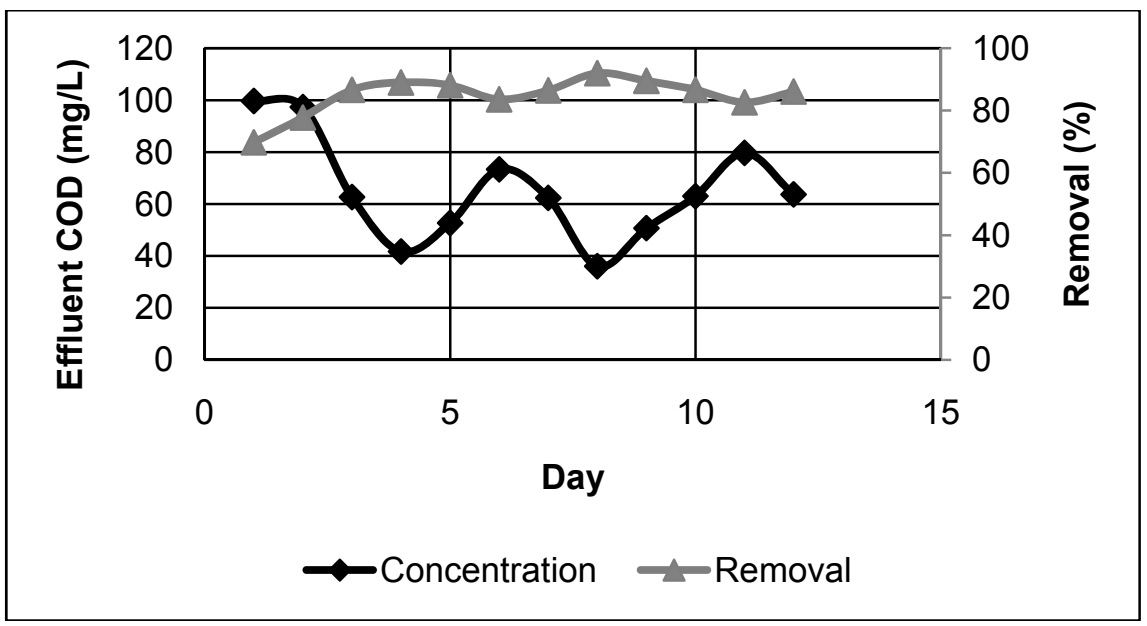

Figure 5: COD removals vs sampling days for SBR aerobic treatment for anaerobic wastewater effluent.

The results are shown in Fig. 6. Influent COD concentration was found to be approximately $378 \mathrm{mg} / \mathrm{L}$ after mixed with domestic wastewater which causes a dilution for the raw wastewater initial concentration and the average effluent COD concentration was found to be approximately $44 \mathrm{mg} / \mathrm{L}$ with an average COD removal of $88 \%$ throughout the study period. 


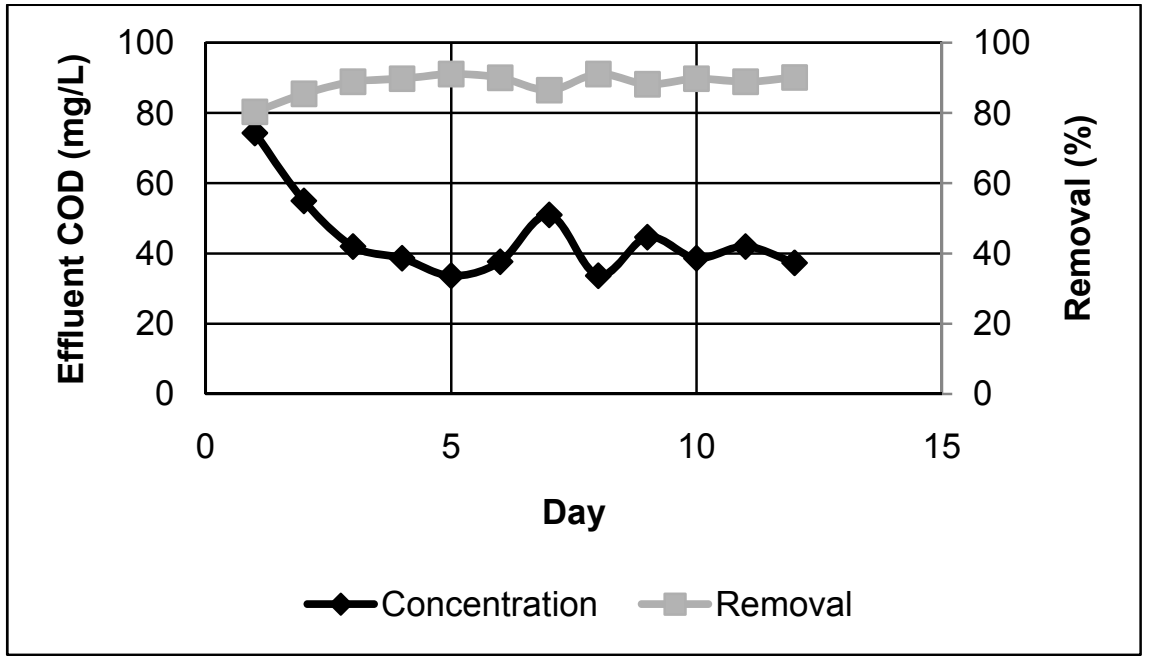

Figure 6: COD removals vs sampling days for SBR aerobic treatment for raw wastewater mixed with domestic wastewater.

\subsection{Comparatives results for SBR systems}

Fig. 7 shows that the results for aerobic reactor, combined anaerobic-aerobic reactors and aerobic mixed with domestic wastewater operated over cycle period of 24 hours, 48 hours, and 24 hours, respectively.

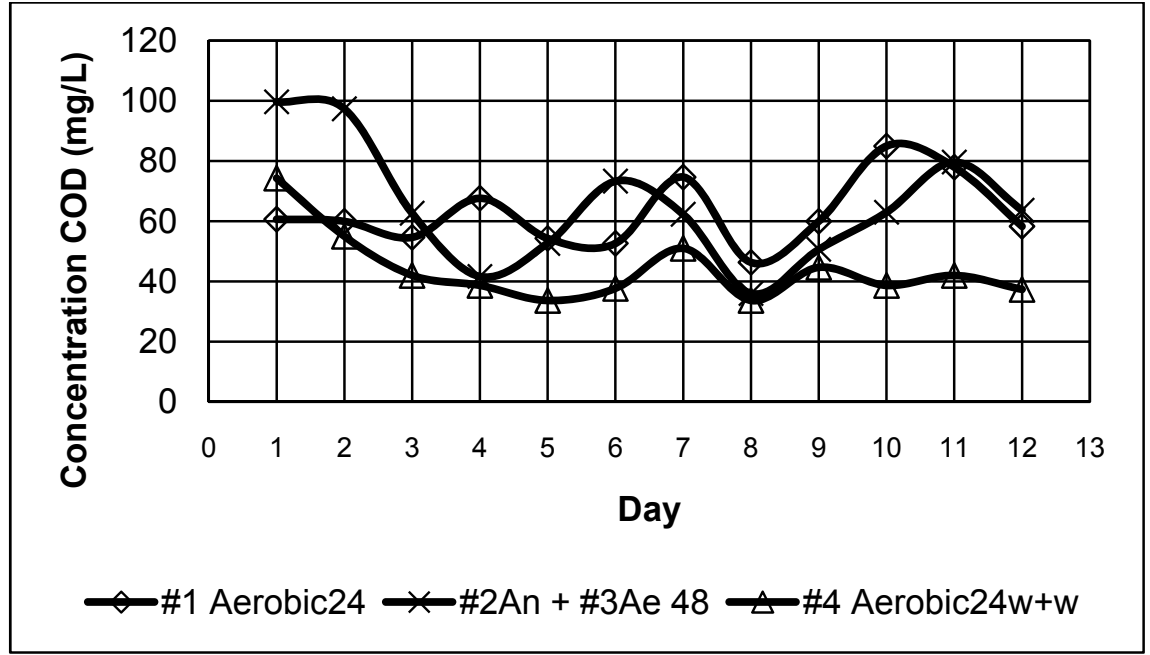

Figure 7: COD concentration vs days for SBR systems treating raw wastewater. 
The average COD removals for the aerobic reactor, combined anaerobicaerobic reactors and aerobic mixed with domestic wastewater achieved were found to be approximately, $91 \%, 91 \%$, and $88 \%$ respectively, with its final average effluent COD of $63 \mathrm{mg} / \mathrm{L}, 65 \mathrm{mg} / \mathrm{L}$, and $44 \mathrm{mg} / \mathrm{L}$, respectively.

\section{Conclusion}

The sequencing batch reactor results show that the desired treatment level for raw wastewater can be achieved. Aerobic SBR reactors reported effluent COD concentration below standard B set by EQA 1974. Highest percentage COD removals were reported in the aerobic system and also in the combined anaerobic-aerobic system. The total cycle for aerobic reactor and the combined system was 24 hours and 48 hours, respectively. Lowest effluent COD concentration was recorded in the aerobic reactor when the wastewater was treated together with domestic wastewater, but the influent was already diluted because of the mixing. Nutrients provided by the domestic wastewater further enhance the treatment. However, further study need to be conducted on the nutritional requirements for the biological study.

\section{References}

[1] Mohamed, A., Z., Walid, E., Characterization and assessment of Al Ruwais refinery wastewater. Journal of Hazardous Materials, A136, pp. 398-405, 2006.

[2] S. Ishak, A. Malakahmad, M. H. Isa, "Biological treatment of refinery wastewater: A review", Proceeding of International Conference on Sustainable Building and Infrastructure (ICSBI 2010), Kuala Lumpur Malaysia. 2010.

[3] M. Bagajewicz, "A review of recent design procedures for water networks in refineries and process plants," Computers \& Chemical Engineering, Volume 24(9-10), pp.2093-2113, 2000.

[4] M. Hatta Dahlan, X-Hui Xing, Y. Yoshikawa and K. Matsumoto, "Analysis of a simple biodegradation process for the removal of volatile organic chemicals from wastewater based on gas stripping principle," Journal of Bioscience and Bioengineering, Volume 87(4), pp. 519-524, 1999.

[5] Mi-Seon Jo, E.r. Rene, Soo-Hong Kim, Hung-Suck Park, "An analysis of synergistic and antagonistic behavior during BTEX removal in batch system using response surface methodology," Journal of Hazardous Materials, Volume 152(3), pp.1276-1284, 2008.

[6] S. Shokrollahzadeh, F. Azizmohseni, F. Golmohammad, H. Shokouhi, F. Khademhaghighat, "Biodegradation potential and bacterial diversity of a petrochemical wastewater treatment plant in Iran" Bioresource Technology, Volume 99(14), pp. 6127-6133, 2008.

[7] Thwe-Htun Khaing, Jianfeng Li, Yaozhong Li, Nyunt Wai, Fook-sin Wong, "Feasibility study on petrochemical wastewater treatment and reuse using a 
novel submerged membrane distillation bioreactor", Separation and Purification Technology, Volume 74(1), pp. 138-143, 2010.

[8] Shailesh S. Shah, Jitendra D. Desai, Cherla Ramakrishna, Navin M. Bhatt, 1998, "Aerobic biotreatment of wastewater from dimethyl terephthalate plant using biomass support particles, Journal of Fermentation and Bioengineering, Volume 86( 2), pp. 215-219, 1998.

[9] Gasim H.A., S.R.M. Kutty, M.H. Isa, "Biodegradability of Petroleum Refinery Wastewater in Batch Reactor", Proceeding of International Conference on Sustainable Building and Infrastructure (ICSBI 2010), Kuala Lumpur Malaysia. 2010. 